\title{
Sosialisasi Aspek Legal Pembelian Obat di Apotek dan Penyuluhan Dagusibu
}

\author{
Socialization of Legal Aspects of Drug Purchase \\ at a Pharmacy and Extension of Dagusibu
}

\author{
Hanari Fajarini $^{1^{*}}$, Yuniarti Dewi Rahmawati ${ }^{2}$, Laila Nur Azizah ${ }^{3}$, Risky Fatikasari ${ }^{4}$ \\ ${ }^{1,3}$ Program Studi Farmasi Fakultas Ilmu Kesehatan Universitas Muhadi Setiabudi \\ 2,4 Program Studi Ilmu Gizi Fakultas Ilmu Kesehatan Universitas Muhadi Setiabudi \\ E-mail:*1hanari.fajarini@gmail.com
}

\begin{abstract}
Abstrak
Peredaran obat-obatan terlarang juga menjadi isu hangat di masyarakat dan merupakan masalah yang krusial, oleh karena itu masyarakat perlu diedukasi tentang aspek legalitas membeli obat di apotek. Ikatan Apoteker Indonesia saat ini mulai melakukan sosialisasi kepada masyarakat tentang penggunaan obat yang baik dan benar. Kegiatan sosialisasi ini diberi nama DAGUSIBU atau Get, Use, Save and Dispose. Metode pelaksanaan kegiatan pengabdian masyarakat ini menggunakan metode ceramah dan tanya jawab. Sosialisasi ini diharapkan dapat membantu masyarakat sekitar dalam memahami aspek hukum pembelian obat di apotek dan mengelola obat dengan baik. Peserta adalah keluarga penerima Program Keluarga Harapan di RT 01 RW 03 Desa Sengon Kecamatan Tanjung Kabupaten Brebes. Penyuluhan diawali dengan penjelasan pengertian obat dan klasifikasi obat. Orangorang ditekankan tentang berbagai jenis narkoba dan cara mendapatkannya. Melalui penjelasan ini diharapkan masyarakat mengetahui dampak dari penggunaan obat yang tidak rasional. Penjelasan kemudian dilanjutkan mengenai berbagai sediaan obat dengan cara penggunaan yang berbeda-beda, serta konsep DAGUSIBU. Pelaksanaan penyuluhan telah dilaksanakan dengan baik dan mendapat respon yang baik dari peserta.
\end{abstract}

Kata kunci: penyuluhan, aspek hukum, obat-obatan terlarang.

\begin{abstract}
The circulation of illegal drugs is also a hot issue in the community and is a crucial problem, therefore the public needs to be educated about the legal aspects of buying drugs at pharmacies. The Indonesian Pharmacists Association is currently starting to launch outreach activities to the public regarding the proper and correct use of drugs. This outreach activity is named DAGUSIBU or Get, Use, Save and Dispose. The implementation method for this community service activity is using the lecture and question and answer method. This socialization is expected to help the local community in understanding the legal aspects of purchasing drugs at pharmacies and managing drugs properly. Participants are families who receive the Program Keluarga Harapan in RT 01 RW 03 Sengon Village, Tanjung District, Brebes Regency. Counseling begins with an explanation of the meaning of drugs and drug classification. People are emphasized about the different types of drugs and how to get them. Through this explanation, it is hoped that the public will know the impact of irrational use of drugs. The explanation then continued regarding the various medicinal preparations with different ways of using them, as well as the DAGUSIBU concept. The implementation of the counseling has been carried out well and received a good response from the participants.

Keywords: counseling, legal aspects, illegal drugs
\end{abstract}

Submitted: Juli 2021, Accepted: Agustus 2021, Published: Agustus 2021

ISSN 2746-6345 (media online) 


\section{PENDAHULUAN}

Pemberlakuan Jaminan Kesehatan Nasional memungkinkan masyarakat mendapatkan akses yang lebih mudah untuk mendapatkan pengobatan. Masyarakat mulai terbiasa dengan penggunaan berbagai jenis obat-obatan yang ditujukan untuk menyembuhkan penyakit, mengontrol atau menjaga kesehatan maupun sebagai suplemen untuk mendukung aktifitas sehari-hari. Faktor lain yang memicu tingginya konsumsi obat di masyarakat diantaranya perkembangan jenis penyakit, ketersediaan jumlah dan item obat maupun suplemen, serta semakin banyaknya jumlah Apotek sehingga masyarakat lebih mudah dalam memperoleh obatobatan. (Endang Soetrisno dan Hanari Fajarini, 2016, p 148). Isu peredaran obat ilegal juga menjadi isu hangat di tengah masyarakat dan menjadi permasalahan yang cukup krusial, oleh karena itu masyarakat perlu juga diedukasi mengenai aspek legal pembelian obat di apotek, dengan harapan masyarakat terhindar dari peredaran obat-obat illegal (Devi Mustika dkk, 2020, p 5-12).

Perkembangan penggunaan obat di masyarakat dapat menimbulkan berbagai dampak, baik positif maupun negatif. Dampak positif yang timbul adalah semakin tingginya kepedulian masyarakat terhadap kesehatan, ini terlihat dari meningkatkan jumlah masyarakat yang memeriksakan diri ke fasilitas pelayanan kesehatan. Sedangkan dampak negatif yang ditimbulkan dengan meningkatnya penggunaan obat di masyarakat adalah potensi kesalahan dalam menggunakan obat, ketidaktepatan dalam menyimpan obat di rumah hingga limbah obat yang dibuang dengan cara yang tidak semestinya. Dampak negatif ini dapat terjadi karena kurangnya pengetahuan mengenai obat-obatan dari masyarakat dan kurangnya informasi yang disampaikan kepada masyarakat terkait penggunaan obat yang baik dan benar. Ketidaktepatan dalam menggunakan obat, menyimpan dan membuang limbah obat dapat menyebabkan kerugian baik bagi masyarakat maupun bagi lingkungan. Keadaan ini dapat diantisipasi dengan pemberian informasi dan edukasi obat kepada masyarakat. (Hanari Fajarini dan Tonasih, 2019, p 3).

Edukasi mengenai penggunaan obat yang baik dan benar sudah dicanangkan oleh Ikatan Apoteker Indonesia (IAI) sebagai salah satu organisasi profesi kesehatan yang menaungi sumber daya kesehatan bidang farmasi. Edukasi yang dimaksud adalah kegiatan penyuluhan atau kampanye dengan slogan DAGUSIBU (Dapatkan - Gunakan - Simpan - Buang). Apoteker sebagai profesi kesehatan yang concern dalam bidang obat-obatan diharapkan secara kontinu dapat mengkampanyekan DAGUSIBU di manapun. Tujuan dari kampanye DAGUSIBU adalah supaya masyarakat dapat lebih memahami mengenai penggunaan obat yang baik dan benar sehingga tujuan terapi dapat tercapai. Tujuan lainnya adalah agar masyarakat memiliki pengetahuan tentang penyimpanan obat yang benar di rumah sehingga tidak merusak sediaan yang dapat mengakibatkan bioavailabilitas dan efikasi obat menjadi berkurang. Tujuan selanjutnya adalah mengurangi timbulnya kerusakan lingkungan akibat pembuangan limbah obat yang tidak tepat. (Hanari Fajarini, 2018, p 260).

Masyarakat di RT 01 RW 03 Desa Sengon Kecamatan Tanjung Kabupaten Brebes saat ini mempunyai akses yang relatif baik terhadap pelayanan kesehatan, termasuk di dalamnya akses dalam memperoleh obat-obatan, baik obat yang diresepkan oleh dokter, obat bebas maupun obat bebas terbatas yang dibeli sesuai dengan gejala penyakit yang timbul. Era Jaminan Kesehatan Nasional (JKN) berimbas pada semakin meningkatnya motivasi masyarakat untuk memeriksakan kesehatan secara rutin di fasilitas pelayanan kesehatan. Fenomena ini menjadi penyebab peredaran obat yang semakin banyak di masyarakat. Meningkatnya konsumsi obat di masyarakat belum ditunjang secara optimal dengan pengetahuan masyarakat mengenai cara konsumsi obat yang baik dan benar, cara menyimpan obat yang benar serta cara membuang limbah obat yang aman dan baik bagi lingkungan. Pemberian informasi mengenai aspek legal pembelian obat di apotek serta edukasi yang masif terkait penggunaan obat menjadi kebutuhan mendasar bagi masyarakat agar terhindar dari dampak buruk penggunaan dan pembuangan limbah obat yang tidak tepat. Peserta dari sosialisasi ini adalah Keluarga Penerima Bantuan Program Keluarga Harapan (PKH) RT 01 RW 03 Desa Sengon Kecamatan Tanjung Kabupaten 
Brebes. Pemilihan peserta dari keluarga penerima PKH dengan pertimbangan supaya kegiatan pengabdian masyarakat yang dilakukan Universitas Muhadi Setiabudi dapat mendukung program pemerintah dan dapat menambah wawasan serta pengetahuan kesehatan bagi keluarga penerima PKH sehingga dapat meningkatkan derajat kesehatan masyarakat.

Kegiatan penyuluhan ini bertujuan agar sebagai berikut.

Peserta penyuluhan dapat memahami aspek legal pembelian obat di apotek;

Peserta penyuluhan dapat memahami tentang pengertian obat, penggolongan obat serta perbedaan obat keras, obat bebas terbatas, obat bebas, dan obat wajib apotek;

Peserta penyuluhan dapat memahami mengenai berbagai macam bentuk sediaan obat serta cara penggunaan masing-masing sediaan untuk memperoleh khasiat yang diinginkan;

Peserta penyuluhan dapat memahami mengenai tata cara menyimpan obat yang benar dan cara membuang limbah supaya aman dan tidak mencemari lingkungan.

Kegiatan ini diharapkan dapat memberikan manfaat dalam upaya meningkatkan pengetahuan masyarakat mengenai aspek legal pembelian obat di apotek serta tata cara yang tepat dalam penggunaan obat, dimulai dari cara mendapatkan obat yang legal, menggunakan atau mengonsumsi obat secara tepat, menyimpan sediaan obat dengan benar di rumah hingga membuang limbah obat dengan tepat agar tidak mencemari lingkungan.

\section{METODE PELAKSANAAN}

Metode pelaksanaan pada kegiatan pengabdian kepada masyarakat ini adalah menggunakan metode ceramah dan Tanya jawab. Adapun materi yang disampaikan adalah sebagai berikut.

Ceramah mengenai aspek legal pembelian obat di Apotek

Ceramah tentang pengertian obat, penggolongan obat dan perbedaan dari masing-masing penggolongan obat;

Ceramah tentang berbagai macam bentuk sediaan obat serta cara penggunaannya secara tepat;

Ceramah mengenai tata cara penyimpanan obat yang benar yang disesuaikan dengan bentuk sediaan serta tata cara pembuangan limbah obat maupun obat yang telah rusak atau kadaluwarsa.

Adapun target dan luaran dari kegiatan ini adalah sebagai berikut.

Peserta penyuluhan memahami aspek legal pembelian obat di apotek serta memahami tata cara pembelian obat yang baik dan benar;

Peserta penyuluhan memahami tentang definisi umum dan klasifikasi obat;

Peserta penyuluhan memahami tentang berbagai macam sediaan obat dan cara konsumsi atau penggunaannya;

Peserta penyuluhan memahami tata cara penyimpanan dan pembuangan obat yang rusak atau kedaluwarsa.

\section{HASIL DAN PEMBAHASAN}

Kegiatan penyuluhan Aspek Legal Pembelian Obat di Apotek dan DAGUSIBU ini mengadopsi dari salah satu dari program promosi kesehatan yang dicanangkan oleh Ikatan Apoteker Indonesia (IAI). Kegiatan ini tengah gencar dilaksanakan oleh apoteker di seluruh Indonesia dalam rangka mengedukasi masyarakat tentang pentingnya memahami penggunaan obat dengan secara tepat. Jumlah konsumsi obat yang semakin meningkat di era JKN ini perlu didukung dengan peningkatan pengetahuan masyarakat mengenai penggunaan dan pengelolaan obat secara tepat, baik untuk obat-obatan yang didapat melalui resep dokter maupun obat-obatan yang dibeli sendiri di apotek. (Devi Mustika dkk, 2020, p 5-12).

Kegiatan sosialisasi atau penyuluhan di RT 01 RW 03 Desa Sengon Kecamatan Tanjung Kabupaten Brebes merupakan salah satu rangkaian kegiatan pengabdian masyarakat. Kegiatan ini diharapkan dapat membantu peserta penyuluhan dalam memahami aspek legal

SOSIALISASI ASPEK LEGAL PEMBELIAN OBAT DI APOTEK DAN PENYULUHAN DAGUSIBU (Hanari Fajarini, Yuniarti Dewi Rahmawati, Laila Nur Azizah, Risky Fatikasari) 
pembelian obat di apotek serta menambah wawasan mengenai pengelolaan obat secara tepat dengan maksud dapat diimplementasikan maupun disebarluaskan di lingkungan keluarga dan masyarakat secara lebih luas. Peserta sosialisasi atau penyuluhan adalah keluarga penerima bantuan Program Keluarga Harapan (PKH) di RT 01 RW 03 Desa Sengon Kecamatan Tanjung Kabupaten Brebes. Rangkaian kegiatan ini dimulai dengan sambutan dan pembukaan kegiatan oleh Ketua RT setempat, dimana Ketua RT memaparkan berkenaan dengan rangkaian kegiatan penyuluhan yang akan dilaksanakan.

Penyuluhan dimulai dengan penjelasan pengertian obat, penggolongan obat yang terdiri atas obat bebas, obat bebas terbatas, obat keras, serta obat wajib apotek serta perbedaan mendasar dari masing-masing penggolongan obat. (Devi Mustika dkk, 2020, p 11). Pada penyuluhan kali ini ditekankan mengenai perbedaan macam-macam atau penggolongan obat tersebut serta bagaimana cara mendapatkannya. Dengan harapan peserta pelatihan dapat menggunakan obat secara tepat. Tujuan lain dari penyuluhan ini diharapkan peserta penyuluhan lebih memahami mengenai dampak negatif dari penggunaan obat secara tidak rasional, semisal bahaya pembelian obat antibiotik tanpa resep dari dokter. Hal ini perlu disampaikan kepada peserta penyuluhan mengingat risiko resistensi antibiotik yang semakin meningkat di dari waktu ke waktu. (Tan Hoan Tjay dan Kirana Rahardja, 2007, p 19) Disamping itu agar peserta pelatihan mengetahui bahaya atau risiko pembelian obat di tempat yang tidak tepat, misal membeli obat di toko kelontong atau tempat tidak resmi lainnya. Pembelian obat bukan di apotek memberi peluang yang semakin besar atas peredaran obat ilegal yang dapat membahayakan kesehatan bagi penggunanya. (Hanari Fajarini dan Atrian Widodo, 2020, p 27).

Kegiatan penyuluhan dilanjutkan tentang berbagai jenis sediaan obat, cara penggunaan obat, metode penggunaan obat untuk sediaan khusus yang membutuhkan perhatian khusus dengan tujuan menghindari kekeliruan dalam penggunaannya. Berbagai bentuk sediaan obat yang dijelaskan penggunaannya antara lain sediaan oral, inhalasi, topikal, ovula, suppositoria, tetes mata dan lain sebagainya. Kesalahan dalam penggunaan obat banyak terjadi diakibatkan oleh beberapa faktor. Salah satunya adalah informasi yang kurang lengkap yang diberikan oleh petugas kesehatan pada saat pemberian obat. Kesalahan penggunaan obat paling banyak terjadi pada kasus-kasus penggunaan sediaan obat yang memerlukan teknik khusus. Misalnya sediaan inhalasi, sediaan injeksi contohnya insulin yang dapat digunakan sendiri oleh pasien di rumah tanpa bantuan dari tenaga kesehatan. Contoh sediaan obat di atas perlu adanya pemberian informasi dan edukasi yang lebih intensif supaya pasien atau masyarakat terhindar dari kesalahan penggunaan obat.

Materi penyuluhan selanjutnya adalah paparan berkenaan dengan tata cara penyimpanan obat dan pembuangan limbah obat dengan baik dan benar. Tata cara penyimpanan sediaan obat perlu mendapat perhatian khusus guna menjaga bioavailabilitas dan efikasi sediaan obat, terutama untuk obat yang digunakan dalam jangka waktu yang panjang (Elin Yulinah Sukandar, 2008, p 121). Obat termasuk ke dalam salah satu produk yang memiliki tingkat sensitifitas yang relatif tinggi terhadap paparan sinar matahari langsung, kondisi tempat penyimpanan yang lembab, ataupun kondisi lainnya yang dapat merusak komponen dari sediaan obat. Kerusakan pada komponen obat dapat berpengaruh pada efek obat, efek yang timbul dapat berupa penurunan bioavailabititas dan efikasi, bahkan tidak jarang menimbulkan efek toksik bagi pasien. Penurunan bioavalilabilitas dan efikasi dapat mengakibatkan pengobatan menjadi tidak optimal (Sulistia Gunawan, 2009, p 29). Hal lain yang menjadi perhatian dalam pengelolaan obat adalah aturan mengenai pembuangan limbah obat, obat yang sudah rusak atau obat kadaluwarsa. Pembuangan limbah obat yang tidak semestinya dapat berpotensi terjadinya penyalahgunaan limbah obat oleh oknum yang tidak bertanggung jawab. Ketentuan pembuangan limbah obat yang benar harus memperhatikan sediaan obat yang akan dibuang, persiapan dan lokasi pembuangan yang aman. Foto kegiatan terdapat pada Gambar 1. 


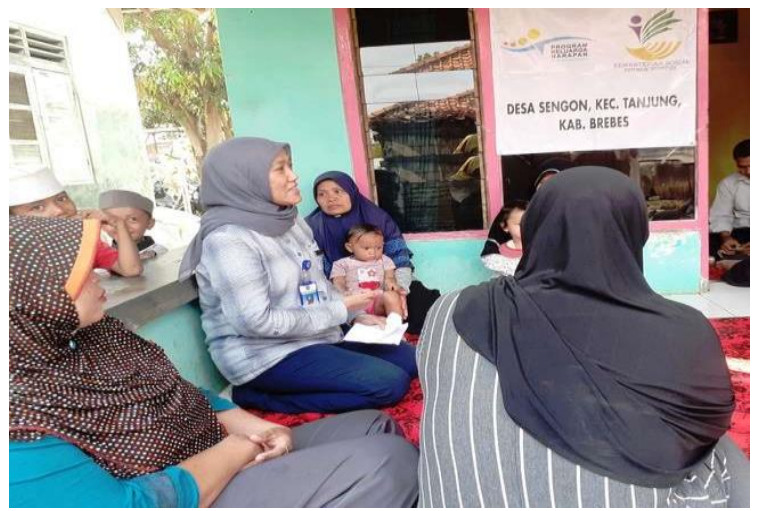

Gambar 1. Kegiatan sosialisasi

Sesi terakhir dari kegiatan penyuluhan adalah sesi tanya jawab, dimana respon dari peserta penyuluhan sangat antusias, ini dapat dilihat dari beberapa pertanyaan yang diajukan kepada pemateri. Pertanyaan yang diajukan merefleksikan rasa ingin tahu dari peserta penyuluhan mengenai pengelolaan obat yang baik dan benar. Diharapkan tujuan kegiatan penyuluhan ini dapat terwujud, harapannya adalah agar masyarakat memiliki pengetahuan yang lebih baik dalam menggunakan dan mengelola obat. Penyuluhan dapat digambarkan pada Gambar 2.

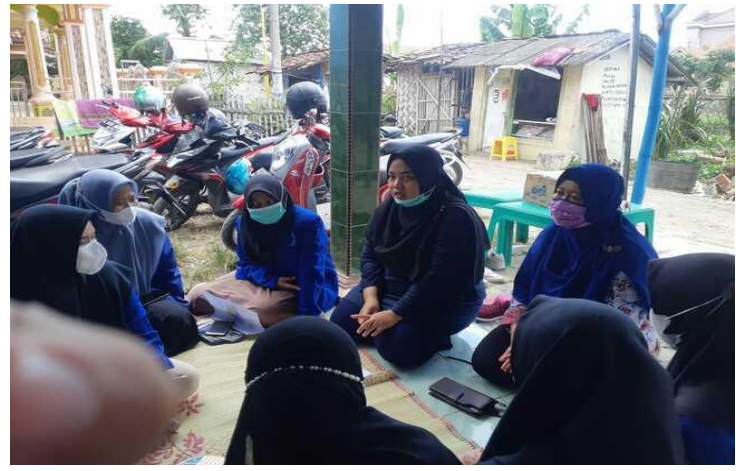

Gambar 2. Kegiatan Penyuluhan

\section{KESIMPULAN}

Pelaksanaan penyuluhan sebagai salah satu program pengabdian kepada masyarakat dengan judul "Sosialisasi Aspek Legal Pembelian Obat di Apotek dan Penyuluhan DAGUSIBU" di RT 01 RW 03 Desa Sengon Kecamatan Tanjung Kabupaten Brebes telah terlaksana dengan baik dan mendapatkan respon yang baik dari peserta penyuluhan.

\section{UCAPAN TERIMAKASIH}

Terima kasih kami sampaikan kepada Universitas Muhadi Setiabudi, Pemerintah Desa Sengon Kecamatan Tanjumh Kabupaten Brebes khususnya RT 01 RW 03, Tenaga Pendamping Program Keluarga Harapan (PKH) dan seluruh peserta kegiatan.

\section{DAFTAR PUSTAKA}

Devi Mustika, Hanari Fajarini, Tya Muldiyana. (2020). Evaluasi Pelayanan Obat Non Resep di Apotek Manjur Desa Petunjungan. Jurnal Ilmiah JOPHUS : Journal Of Pharmacy UMUS. 1 (2). page 5-12.

Elin Yulinah Sukandar, dkk. (2008). Iso Farmakoterapi. PT ISFI Penerbitan. Jakarta. Hal 121. Gunawan, Sulistia, dkk. (2009). Farmakologi dan Terapi. Edisi V. Jakarta. FKUI.

Endang Sutrisno and Hanari Fajarini. (2016). Legal Culture Of Pharmacist In The Perspective Of Pharmaceutical Services Standard In Pharmacies. Jurnal Dinamika Hukum, 16(2), page 
151.

Hanari Fajarini dan Tonasih. (2019). Pola Penggunaan Antihipertensi Pada Pasien Rawat Jalan di Puskesmas Siwuluh Kabupaten Brebes. Jurnal Ilmiah JOPHUS: Journal Of Pharmacy UMUS. 1 (1). page 1-6.

Hanari Fajarini. (2018). Implementasi Peraturan Menteri Kesehatan RI No. 73 Tahun 2016 Tentang Standar Pelayanan Kefarmasian di Apotek. Jurnal Para Pemikir. 7 (2). page 260269.

Hanari Fajarini dan Atrian Widodo. (2020). Evaluasi Legalitas dan Kelengkapan Administratif Resep Pada Rumah Sakit di Kabupaten Brebes. Jurnal Ilmiah JOPHUS: Journal Of Pharmacy UMUS. 9 (2). page 26-32.

Tjay, Tan Hoan dan Raharja, Kirana. (2007). Obat-Obat Penting. Edisi 6. Cetakan Pertama. Jakarta. PT Elex Media Komputindo. 